\title{
Influence of Microcapsule Size and Shell Polarity on the Time-Dependent Viscosity of Geopolymer Paste
}

Cao, Vinh Duy; Pilehvar, Shima; Salas-Bringas, Carlos; Szczotok, Anna M.; Do, Nu Bich Duyen; Le, HT; Carmona, Manuel; Rodriguez, Juan F.; Kjøniksen, Anna-Lena

Published in:

Industrial and Engineering Chemistry Research

Link to article, DOI:

10.1021/acs.iecr.8b01961

Publication date:

2018

Document Version

Publisher's PDF, also known as Version of record

Link back to DTU Orbit

Citation (APA):

Cao, V. D., Pilehvar, S., Salas-Bringas, C., Szczotok, A. M., Do, N. B. D., Le, HT., Carmona, M., Rodriguez, J. F., \& Kjøniksen, A-L. (2018). Influence of Microcapsule Size and Shell Polarity on the Time-Dependent Viscosity of Geopolymer Paste. Industrial and Engineering Chemistry Research, 57(29), 9457-9464.

https://doi.org/10.1021/acs.iecr.8b01961

\section{General rights}

Copyright and moral rights for the publications made accessible in the public portal are retained by the authors and/or other copyright owners and it is a condition of accessing publications that users recognise and abide by the legal requirements associated with these rights.

- Users may download and print one copy of any publication from the public portal for the purpose of private study or research.

- You may not further distribute the material or use it for any profit-making activity or commercial gain

- You may freely distribute the URL identifying the publication in the public portal 


\section{Influence of Microcapsule Size and Shell Polarity on the Time- Dependent Viscosity of Geopolymer Paste}

Vinh Duy Cao, ${ }^{\dagger, \ddagger \odot ~ S h i m a ~ P i l e h v a r, ~}{ }^{\dagger, \S}$ Carlos Salas-Bringas, ${ }^{\dagger}$ Anna M. Szczotok, ${ }^{\dagger, \|}$ Nu Bich Duyen Do, ${ }^{\perp}$

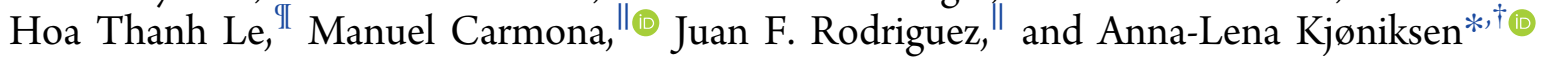

${ }^{\dagger}$ Faculty of Engineering, Østfold University College, N-1757 Halden, Norway

${ }^{\ddagger}$ Faculty of Science and Technology, Norwegian University of Life Sciences, N-1432 Ås, Norway

${ }^{\S}$ Department of Material Engineering and Manufacturing, Technical University of Cartagena, 30202 Cartagena, Murcia, Spain

"Department of Chemical Engineering, University of Castilla - La Mancha, 13004 Ciudad Real, Spain

${ }^{\perp}$ Faculty of Technology, Natural Sciences and Maritime Sciences, University College of Southeast Norway, N-3184 Borre, Norway

II Department of Micro and Nanotechnology, DTU Nanotech, Technical University of Denmark, 2800 Kongens Lyngby, Denmark

\section{Supporting Information}
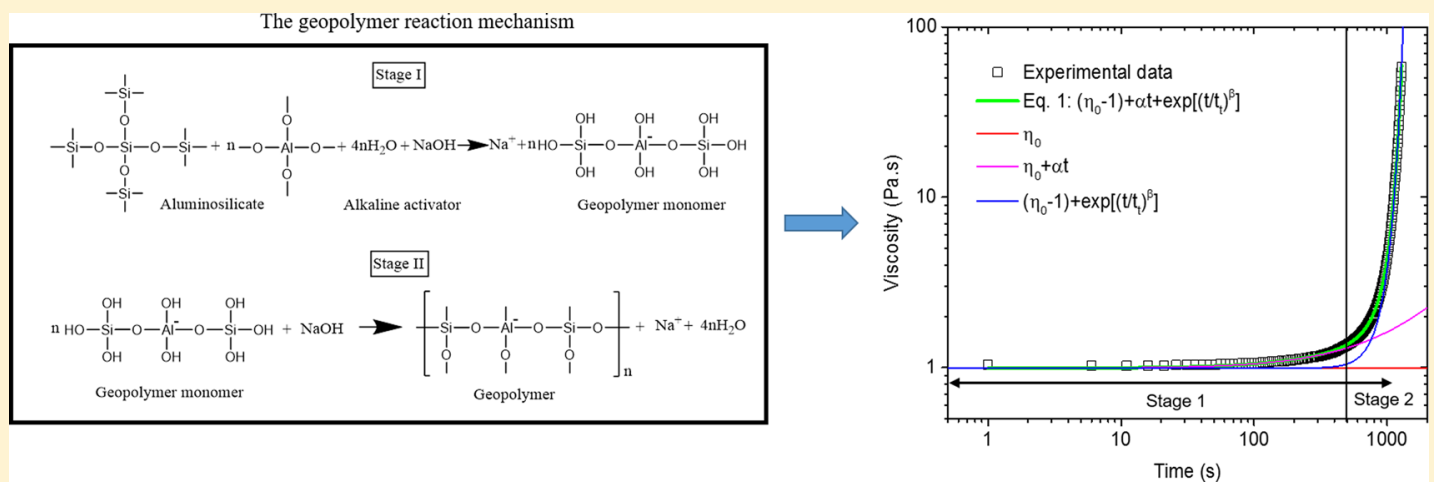

ABSTRACT: The effects of microencapsulated phase-change materials (MPCM) on the rheological properties of a geopolymer paste (GPP) were investigated. In order to quantify the time-dependent viscosity increase of the geopolymer paste containing MPCM (GPP-MPCM), a new rheological model was successfully developed. Three different MPCMs were compared in order to examine the effect of the hygroscopic nature of the microcapsule shells and the size distribution of the microcapsules. In addition, the effect of microcapsule concentration was investigated. It was found that microcapsules with polar functional groups on the shells affect the viscosity and the geopolymerization reaction of the geopolymer paste much more than microcapsules with hydrophobic shells. In addition, aggregated microcapsules influence the viscosities less than unaggregated microcapsules.

\section{INTRODUCTION}

Portland cement is one of the most important components in building materials because of its important role in producing high-performance concrete. However, producing this cement emits a huge amount of $\mathrm{CO}_{2}$ into the environment. ${ }^{1,2}$ This contributes to around $5-8 \%$ of the total worldwide $\mathrm{CO}_{2}$ emission into the atmosphere. ${ }^{1,3}$ Geopolymers synthesized by alkali activation of aluminosilicate in amorphous form (from industrial waste materials) have recently received considerable attention as an environmentally friendly material to partly replace Portland cement. ${ }^{4,5}$ By replacing Portland cement with a geopolymer, $\mathrm{CO}_{2}$ emission from the cement industry can be significantly reduced.

Approximately $40 \%$ of the total global energy consumption is from buildings; therefore, the reduction of energy consumption by buildings is important for the environment., Phase-change materials (PCM), with the capability of storing and releasing high amounts of energy around the phase-change temperature, have been integrated into building materials to enhance the thermal performances of buildings. However, the practical applications are limited because of reactions with surrounding materials, which cause reductions of the mechanical strength of the building materials and deteriorate the thermal properties of PCM. ${ }^{8,9}$ In order to avoid these adverse interactions, the PCM can be incorporated into protective microcapsules. Microencapsulated phase-change materials (MPCM) have therefore been utilized for integration into building materials to improve the heat-storage capacity and thermal insulation. ${ }^{9-13}$ This is a promising solution to

Received: $\quad$ May 4, 2018

Revised: June 25, 2018

Accepted: June 26, 2018

Published: June 26, 2018 
Table 1. Composition of the Geopolymer Pastes (GPPs) Utilized in the Rheology Measurements

\begin{tabular}{|c|c|c|c|c|c|c|}
\hline sample & MPCM (wt \%) & alkaline solution $(\mathrm{g})$ & water $(\mathrm{g})$ & FA $(\mathrm{g})$ & GGBFS (g) & $\operatorname{MPCM}(\mathrm{g})$ \\
\hline GPP0 & 0 & 220 & 55 & 300 & 200 & 0 \\
\hline GPP3 & 3 & 220 & 55 & 300 & 200 & 24 \\
\hline GPP6 & 6 & 220 & 55 & 300 & 200 & 50 \\
\hline GPP9 & 9 & 220 & 55 & 300 & 200 & 77 \\
\hline GPP12 & $12^{a}$ & 220 & 55 & 300 & 200 & 106 \\
\hline
\end{tabular}

${ }^{a} \mathrm{MF} / \mathrm{PCM} 24$ was not utilized at 12 wt $\%$ because its viscosity was too high.

enhance the energy efficiency of buildings. It is, however, important to ensure that the microcapsules do not break during the mixing process, ${ }^{14}$ as this will adversely affect the thermal properties ${ }^{15}$ and is expected to influence the rheological behavior. ${ }^{16}$ The integration of MPCM into geopolymer materials has been investigated in recent years, showing promising results for reducing the energy consumption of buildings. ${ }^{11-13}$ For incorporation into geopolymers, the MPCM should be able to withstand the highly alkaline environment of the geopolymer mixture. Previous investigations have mainly focused on the thermal and mechanical properties as well as the energy efficiency of these materials. However, studies on the effects of microencapsulated phase-change materials on the rheological properties and geopolymerization reaction of geopolymer pastes are scarce, even though the rheological behavior is important for the geopolymer properties. Previous studies revealed a correlation between rheology and the geopolymerization reaction of a geopolymer paste, where an increase in viscosity as a function of time corresponded to each geopolymerization stage. ${ }^{17}$ Therefore, it is possible that the influence of microcapsules on the geopolymerization reaction can be investigated through their effect on the time-dependent viscosity.

In this article, a geopolymer paste is employed for the integration of microencapsulated phase-change materials. Special attention is focused on the influence of the hygroscopic nature of the polymer shells, the size distribution, and the microcapsule concentration on the geopolymerization reaction and time-dependent viscosity of the geopolymer paste. In order to quantify the time-dependent changes of the viscosities of the MPCM-geopolymer paste and the geopolymerization reaction, a new empirical equation that provides a good representation of the experimental data has been proposed. In addition, the microstructure of the geopolymer paste (GPP) containing the microcapsules was determined by SEM to evaluate whether the microcapsules can withstand the mixing process.

\section{EXPERIMENTAL SECTION}

2.1. Materials. A geopolymer paste containing microencapsulated phase-change materials (MPCM-GPP) was fabricated by mixing fly ash (FA, Norcem), ground granulated blast-furnace slag (GGBFS, Cemex), MPCM, and an alkaline activator solution that was a mixture of $120 \mathrm{~g}$ of a sodium silicate solution ( $35 \mathrm{wt} \%$ solids) and $80 \mathrm{~g}$ of a $14 \mathrm{M} \mathrm{NaOH}$ solution. The recipe of the GPP is shown in Table 1 . The MPCM concentration, which was calculated as the weight percentage of the total geopolymer paste, was varied from 0 to 12 wt \% in steps of 3 wt \%. However, MF/PCM24 was not utilized at a concentration of $12 \mathrm{wt} \%$ because it had too high a viscosity for measurements.
Three different kinds of microcapsules were utilized. PS$\mathrm{DVB} / \mathrm{RT} 27$ is composed of a paraffin Rubitherm RT27 core coated with a shell of polystyrene cross-linked with divinylbenzene (PS-DVB). ${ }^{18}$ Micronal DS-5038X (Microtek, USA) is composed of a paraffin-mixture core and a highly cross-linked poly(methyl methacrylate) (PMMA) shell. ${ }^{19}$ Microtek MPCM24D (Microtek) is composed of a paraffinmixture core and a melamine-formaldehyde polymer shell (MF). ${ }^{20}$ Table 2 summarizes the properties of the three MPCMs.

Table 2. Fundamental Data of the Microencapsulated Phase-Change Materials

$\begin{array}{llcc}\text { MPCM name } & \begin{array}{c}\text { functional groups on } \\ \text { the shell }\end{array} & \begin{array}{c}\text { melting } \\ \text { point }^{a}\left({ }^{\circ} \mathrm{C}\right)\end{array} & \begin{array}{c}\text { latent heat } \\ (\mathrm{J} / \mathrm{g})\end{array} \\ \text { PS-DVB/RT27 } & \text { phenyl (nonpolar) } & 24.9 & 100 \\ \text { PMMA/PCM26 } & \text { ester (polar) } & 24.7 & 110 \\ \text { MF/PCM24 } & \text { amine (polar) } & 21.9 & 154\end{array}$

${ }^{a_{T}}$ The melting points and latent heats were determined by differentialscanning calorimetry (see the Supporting Information for details).

2.2. Rheology. Rheological measurements were carried out using an Anton Paar MCR302 rheometer. The MPCMgeopolymer pastes were tested using a building-materials-cell (BMC-90) measuring system (cup diameter: $74 \mathrm{~mm}$; bob diameter: $59 \mathrm{~mm}$, stirrer ST59-2 V-44.3/120) mounted in a cylindrical Peltier system for temperature control.

The MPCM can be broken during the concrete-mixing process, leading to leaching of PCM. ${ }^{14}$ The nonencapsulated PCM can have a significant effect on the geopolymer properties. Nonencapsulated PCM can contribute to agglomeration of the microcapsules, leading to a decrease of the mechanical properties, reduced thermal performance of the concrete, 9,11 and an increase of the viscosity of the mixture. ${ }^{16}$ Although the PCM (paraffin) in the current study is inert to the concrete environment (an alkaline solution), ${ }^{9}$ it might retard the geopolymerization reaction by coating the binder particles (FA/GGBFS). ${ }^{21}$ It is therefore important to prevent rupture of the MPCM, to avoid interference of nonencapsulated PCM in the rheological properties of the geopolymer.

In order to avoid MPCM damage, FA, GGBFS, and MPCM were gently mixed together at room temperature $\left(20 \pm 1{ }^{\circ} \mathrm{C}\right)$ for 1 min using a mixer (Electrolux EKM4300). The alkaline solution and water were added continuously into the mixed powder for $30 \mathrm{~s}$, and the geopolymer paste was mixed for 3 more minutes. After mixing, the geopolymer paste was loaded into the rheometer measuring cell. The sample was left in the cell for $30 \mathrm{~s}$ before being presheared at $50 \mathrm{~s}^{-1}$ for $1 \mathrm{~min}$ to ensure that the samples had the same shear histories. After the preshear, the samples were left to equilibrate for $1 \mathrm{~min}$ to achieve a uniform state. The MPCM-geopolymer paste was 
sheared at a constant shear rate of $10 \mathrm{~s}^{-1}$ until the viscosity increased too much to continue the measurements. The testing temperature was set at $20{ }^{\circ} \mathrm{C}$, which is close to room temperature and below the melting point of the phase-change materials, to minimize the possibility of rupturing the microcapsules during the rheology test.

In order to quantify the time-dependent changes of the viscosities, a new empirical equation (eq 1) was developed:

$$
\eta(t)=\left(\eta_{0}-1\right)+\alpha t+\exp \left[\left(\frac{t}{t_{t}}\right)^{\beta}\right]
$$

where $\eta(t)$ and $\eta_{0}$ are the viscosity as a function of time $(t)$ and the initial viscosity of the MPCM-geopolymer paste, respectively. $\alpha, \beta$, and $t_{t}$ are the kinetic constants for the initial linear viscosity increase, the exponential-growth kinetic constant, and the transition time from linear increase to exponential growth, respectively.

2.3. Geopolymer-Paste Temperature during Geopolymerization. After being mixed, the geopolymer paste without MPCM and with $6 \mathrm{wt} \% \mathrm{MPCM}$ were casted into a mold $(50 \times 50 \times 50 \mathrm{~mm})$ that was made of $20 \mathrm{~mm}$ thick wood with an open top surface. The temperature change of the geopolymer paste during the geopolymerization process was recorded using thermocouple type $\mathrm{T}$ (Omega) via a multichannel multimeter (LR8410-20, Hioki). The thermocouple was inserted into the center of the geopolymer-paste sample after casting. The data was recorded every $0.5 \mathrm{~s}$ for a period of $5 \mathrm{~h}$. The test was conducted at room temperature $\left(20 \pm 1{ }^{\circ} \mathrm{C}\right)$. The temperature of the geopolymer paste during the mixing period was not recorded. The temperature increment due to the exothermic geopolymerization reaction during the mixing process was determined as the difference between the room temperature $\left(20 \pm 1{ }^{\circ} \mathrm{C}\right)$ and the geopolymer-paste temperature after the mixing process.

2.4. Size Distribution of MPCM. Low-angle laser-lightscattering (LALLS) laser diffraction using a Malvern Mastersizer 2000 (Malvern Instruments Ltd.) equipped with a Scirocco 2000 unit for analyzing dispersions of the particles in air was employed to determine the size distribution of the MPCMs.

2.5. Trapped-Water Test. The dispersion of microcapsules $(5.0 \pm 0.1 \mathrm{~g})$ and alkaline solution $(50 \mathrm{~mL})$ was fabricated at room temperature $\left(20 \pm 1{ }^{\circ} \mathrm{C}\right)$ to compare the polarity of the polymer shell with the ability of the microcapsules to trap water. After immersing the MPCM in an alkaline solution for $24 \mathrm{~h}, \mathrm{MPCM}$ was separated from the alkaline solution by centrifugation (Mega Star 1.6R) of the suspension in filter test tubes $(0.45 \mu \mathrm{m}$ filter membrane) at $4500 \mathrm{rpm}$ for $5 \mathrm{~min}$. Afterward, the remaining trapped water on the MPCM was determined by a moisture analyzer ( $\mathrm{MB}$ $64 \mathrm{M}-\mathrm{VWR}$ ) at $70{ }^{\circ} \mathrm{C}$ to gently remove the adsorbed water without damaging the MPCM or degrading the PCM core.

2.6. Scanning Electron Microscopy. The microstructure and the surface morphology of the microcapsules in powder form was examined by scanning electron microscopy (SEM, Quanta FEG-250).

In order to determine the effect of the mixing process and the shear induced during the rheology measurements on the structure of the microcapsules, the microstructure of GPP containing 6 wt \% microcapsules was investigated by SEM (Zeiss Supra $40 \mathrm{VP}$ ) at an accelerating voltage of $15 \mathrm{kV}$. Backscattered-electrons (BSE) mode was utilized to obtain good contrast between the microcapsules and the geopolymer matrix. For this test, the GPP containing 6 wt \% microcapsules was collected after the rheology test of the sample.

\section{RESULTS AND DISCUSSION}

The size distribution and SEM images of the three types of microcapsules are shown in Figure 1. The SEM images show

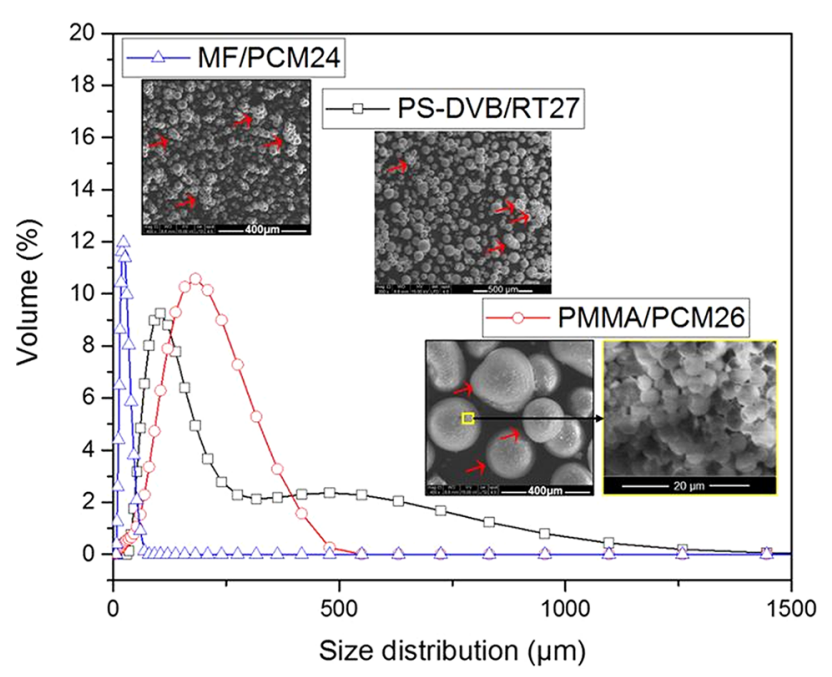

Figure 1. Size (diameter) distribution of the PS-DVB/RT27, PMMA/ PCM26, and MF/PCM24 microcapsules (including aggregates) together with SEM images of the microcapsules. The red arrows show the microcapsule aggregates.

that PS-DVB/RT27, PMMA/PCM26, and MF/PCM24 exhibit spherical shapes with a strong tendency to form agglomerated structures (red arrows), especially PMMA/ PCM26. The diameters of the single microcapsules, which were determined by SEM (Supporting Information), are in the ranges of $10-100,1-3$, and $10-30 \mu \mathrm{m}$ for PS-DVB/RT27, PMMA/PCM26, and MF/PCM24, respectively. However, the mean agglomerated-microcapsule diameters determined by a Mastersizer are $130 \mu \mathrm{m}$ for PS-DVB/RT27, $155 \mu \mathrm{m}$ for PMMA/PCM26, and $21 \mu \mathrm{m}$ for MF/PCM24. The differences in the size distributions of the three kinds of microcapsules may have an important impact on the rheological properties and geopolymerization properties of the geopolymer paste.

After immersing the MPCM in an alkaline solution (corresponding to the alkaline solution used in the geopolymer) for $24 \mathrm{~h}$, the microcapsules remained stable, with a spherical shape and the same size as before (single microcapsules), (see Supporting Information Figure S3). This demonstrates that the microcapsules can withstand the alkaline solution of the geopolymer paste. This is in good agreement with previous findings. ${ }^{9}$ The trapped water in the microcapsule structure is presented in Figure 2. Under alkaline conditions, the amount of trapped water is lowest for PS-DVB/RT27 and highest for PMMA/PCM26. Both the differences in the chemical structure of the polymer shells (Figure 2) and the size of the MPCM (Figure 1) can contribute to this. A higher amount of water is expected to be adsorbed on polymer shells containing polar functional groups compared with nonpolar shells. Accordingly, the nonpolar phenyl groups of PS-DVB are expected to adsorb less water than the polar groups of PMMA (ester groups) and MF (amine groups), which is in agreement with Figure 2. In addition, small particles have a larger surface 


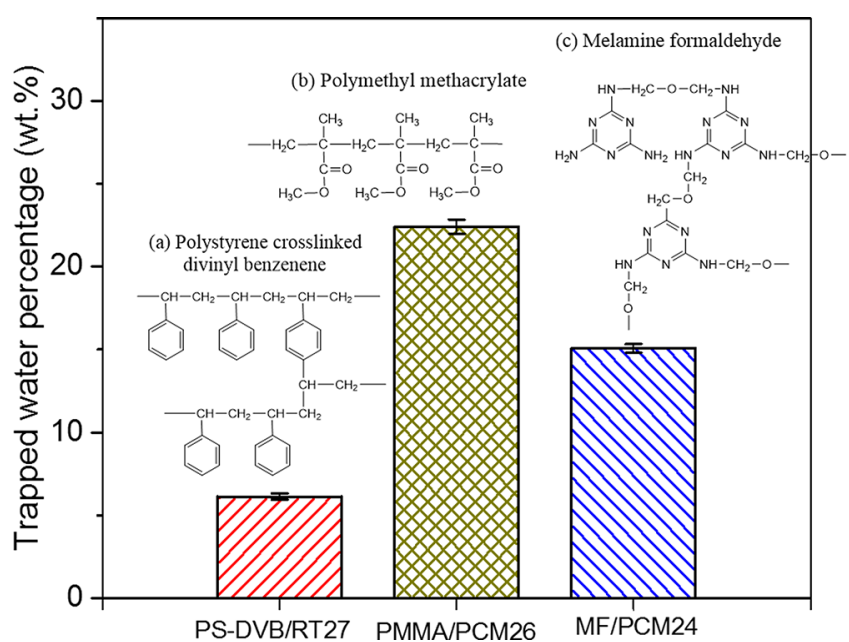

Figure 2. Effect of polymer-shell structure on the trapped water of the microcapsules. The inserted images show the chemical structures of (a) polystyrene cross-linked divinyl benzene (PS-DVB), (b) poly(methyl methacrylate) (PMMA), and (c) melamine formaldehyde (MF).

area per unit volume and can therefore adsorb more water on the surfaces of the particles. The smaller size of a single PMMA/PCM26 microcapsule $(1-3 \mu \mathrm{m})$ compared with a single MF/PCM24 microcapsule $(10-30 \mu \mathrm{m})$ can explain why PMMA/PCM26 exhibits the highest amount of trapped water. The different polarities of PMMA and MF might also play a role, ${ }^{22}$ but unfortunately, the exact differences in polarities are unknown. To determine the exact polarity of each kind of microcapsule would be interesting for further studies.

The temperature of the geopolymer paste after the mixing process was recorded for a period of $5 \mathrm{~h}$ (Figure 3). The

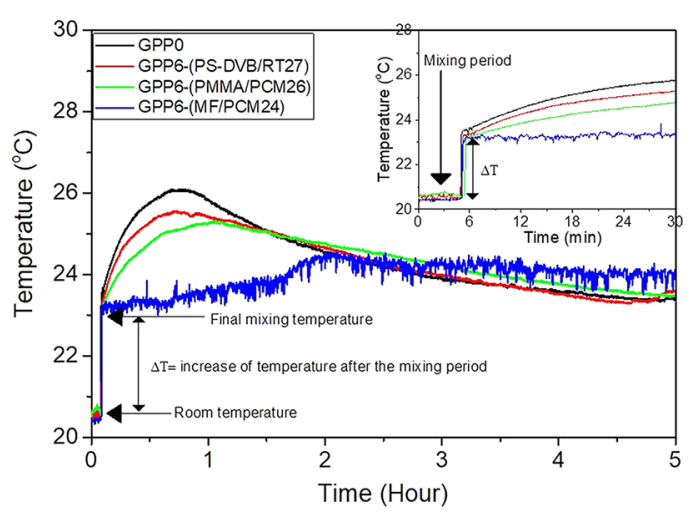

Figure 3. Temperature of geopolymer paste containing 6 wt $\%$ microcapsules during the first $5 \mathrm{~h}$ after mixing. The inserted graph shows a magnification of the first $30 \mathrm{~min}$. The temperature of the geopolymer paste was not recorded during the mixing process.

temperature of the geopolymer paste increased from room temperature $\left(20 \pm 1{ }^{\circ} \mathrm{C}\right.$ before mixing) to approximately 23 ${ }^{\circ} \mathrm{C}$ after the mixing process. The temperature increase during the mixing process is due to the exothermic geopolymerization process. ${ }^{23}$ The temperature of the geopolymer paste continued to increase after the mixing stage. For geopolymer paste without MPCM, a peak was reached at approximately $26^{\circ} \mathrm{C}$. This is in good agreement with Suwan et al., who studied the internal heat liberation of geopolymers at ambient curing conditions. $^{23}$ As can be seen from Figure 3, the peak temperature decreased after the addition of microcapsules. The microcapsules can absorb a high amount of heat during the phase change, which can reduce the temperature increase of the GPP. ${ }^{14}$ The lowest peak temperature (about $24{ }^{\circ} \mathrm{C}$ ) and longest time to reach the peak $(2 \mathrm{~h})$ was observed for GPP containing MF/PCM24, which has the highest latent heat (Table 2). In addition, MF/PCM24 has the lowest melting temperature $\left(21.9^{\circ} \mathrm{C}\right)$, which is closest to the temperature of the geopolymer paste. However, the latent heat of the microcapsules is not the only mechanism that might cause the reduced temperature of the geopolymer paste. It is also possible that the addition of microcapsules might interfere with the geopolymerization reaction, thereby reducing the heat release and peak temperature of the geopolymer paste. Further studies are needed to explore this possibility in more detail.

SEM images of MPCM-GPP with 6 wt \% microcapsules are shown in Figure 4. Most of the single microcapsules were

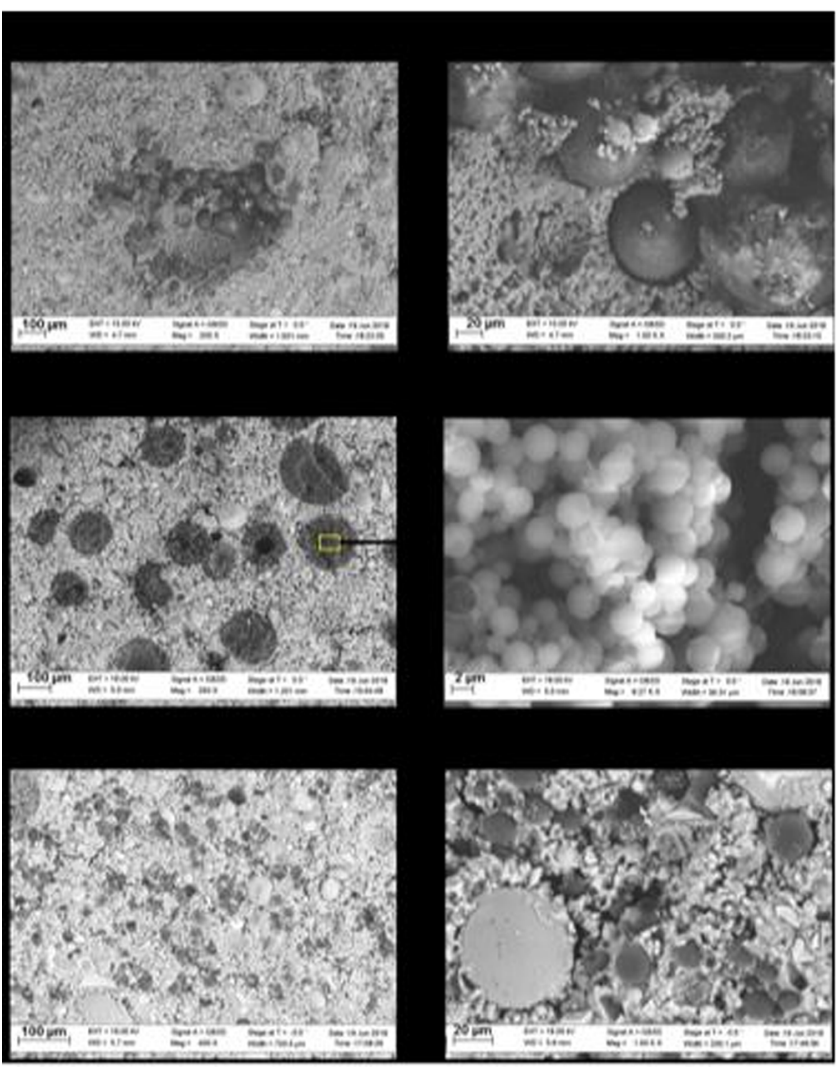

Figure 4. SEM images of geopolymer paste containing 6 wt \% microcapsules: (a) GPP6-(PS-DVB/RT27), (b) GPP6-(PMMA/ PCM26), and (c) GPP6-(MF/PCM24).

observed to be stable after the mixing process. There is no evidence of any cracks in the microcapsules, and no leached PCM is observed on the structures of the microcapsules. This demonstrates that the microcapsules can withstand the current mixing process, even though the exothermic-reaction heat of the geopolymerization process will cause the PCM to be in a liquid state during the mixing process. This is in good agreement with previous studies, where the MPCM remained stable after concrete-, mortar-, and cement-paste mixing. ${ }^{24-27}$ However, this observation is different from that of Hunger et al., ${ }^{14}$ who reported that microcapsules were damaged after the concrete-mixing process. This was explained by the intensive 
mixing of a horizontal concrete mixer, which can produce a high shear stress on the microcapsules. The absence of sand and gravel combined with a relatively gentle mixing force in the current study probably contributes to the prevention of microcapsule rupture during the mixing process. In addition, the mechanical strength of the utilized microcapsules contributes to their ability to withstand the mixing process.

Rheology of MPCM-Geopolymer Paste. The geopolymer binder is an inorganic material based on the polymerization of aluminosilicate materials and a concentrated alkaline solution (Figure 5). The polymerization process
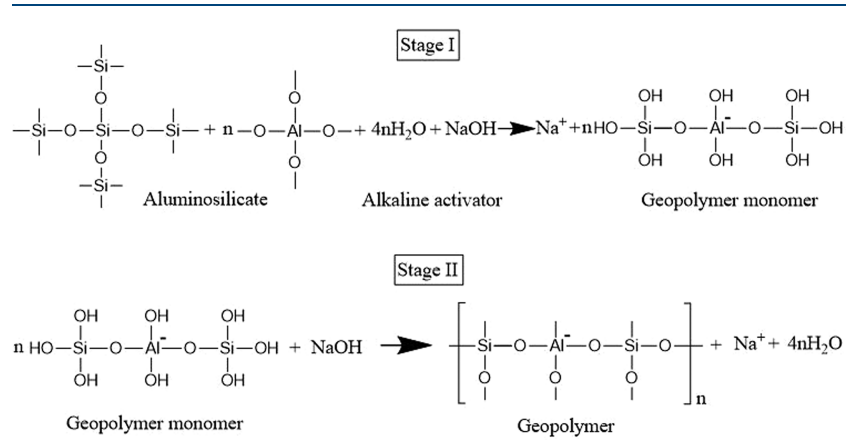

Figure 5. Geopolymer-reaction mechanism between the sodium hydroxide activator and the $\mathrm{Si}-\mathrm{Al}$ source materials.

includes two stages. In Stage I, Si and $\mathrm{Al}$ atoms from the source material react with hydroxide ions to form geopolymer precursor ions (monomers). In Stage II, the precursor ions (monomers) polymerize to form the 3-D geopolymer structure. $^{28,29}$

Figure 6a illustrates how the viscosity changes during the different stages of the geopolymerization procedure. After the initial 7 min mixing procedure (see the Experimental Section for details), the viscosity measurements were started. Each stage of the polymerization process (Figure 5) can be correlated to the time-dependent viscosity of the geopolymer paste. Accordingly, the viscosity of the geopolymer paste as function of time includes two main regions:

Stage I: The viscosity increases linearly with time as a result of the formation of the higher-molecular-weight precursor or monomer.
Stage II: The polymerization process that forms 3-D geopolymer structures dominates the viscosity profile, causing an exponential growth of the viscosity. This is consistent with previous findings. ${ }^{17}$

By utilizing eq 1 , it is possible to quantify these two stages, and evaluate the effect of microcapsules on the polymerization process of a geopolymer paste. The experimental data of the viscosity versus time of the geopolymer paste after adding 0 and 6 wt \% microcapsules (PS-DVB/RT27, PMMA/PCM26, and MF/PCM24) at a shear rate of $10 \mathrm{~s}^{-1}$ is shown in Figure $6 \mathrm{~b}$ together with lines fitted by eq 1 .

The various parts of the fitting function are illustrated in Figure $7 \mathrm{a}$. The figure is plotted on a $\log -\log$ scale to better show the effects at short times and low viscosities. The initial viscosity $\left(\eta_{0}\right)$ shows where the viscosity starts at the beginning of the measurements. The $\eta_{0}$ obtained from the fitting procedure corresponds well with the initial values of the viscosities measured at short times. During Stage I, the viscosity increases linearly $\left(\eta=\eta_{0}+\alpha t\right)$. When Stage II of the geopolymerization reaction starts to dominate, an exponential increase is observed. Because the exponential equation starts at 1 when $t$ approaches $0,-1$ is introduced in the fitting function to obtain the correct value of $\eta_{0}$ from the fitting procedure. A stretched exponential is used, where the exponent, $\beta$, indicates how fast the viscosity is increasing. A higher $\beta$ value indicates a steeper increase of the viscosity.

The new model (eq 1) was found to fit well with the experimental data, as illustrated by the high values of $R^{2}$ $(0.99-1)$ and the fitted lines that follow the experimental data very well both in linear and logarithmic plots (Figures 6 and 7). In order to further examine how well the equation describes the experimental data, residual plots are shown in Figure $7 \mathrm{~b}$. The residuals are mostly nonsystematic, illustrating that the equation provides a good fit of the data. The large values and small peaks in the residuals at long times are due to the transition between Stage I and Stage II combined with the higher viscosity values at long times.

Figure 8 shows the parameters from the fits by eq 1 . The concentration and the type of microcapsule have a significant effect on the polymerization reaction of the geopolymer paste. The fitted parameters show that an increase in the microcapsule concentration causes a higher initial viscosity $\left(\eta_{0}\right.$, Figure $8 \mathrm{a}$ ). This is probably due to the increase of the total surface area of the particles in the geopolymer paste after
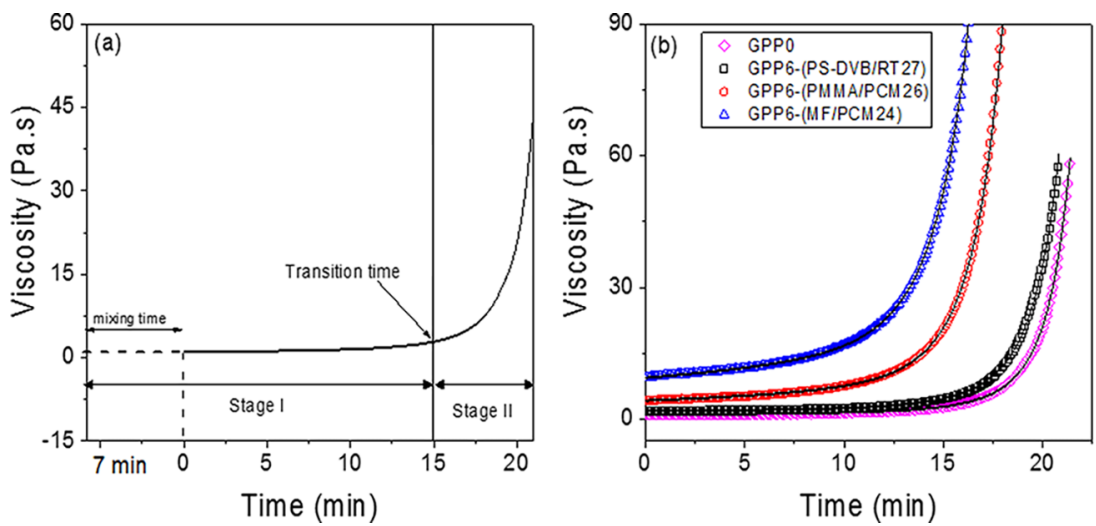

Figure 6. (a) Illustration of the stages of the formation of the geopolymer paste related to the viscosity as function of time. (b) Viscosity of the geopolymer paste without MPCM and with $6 \mathrm{wt} \% \mathrm{MPCM}$ as functions of time at $20{ }^{\circ} \mathrm{C}$ and measured at a shear rate of $10 \mathrm{~s}^{-1}$. The symbols are experimental values (every fifth point is shown). The lines are fitted by eq 1 . 
(a)
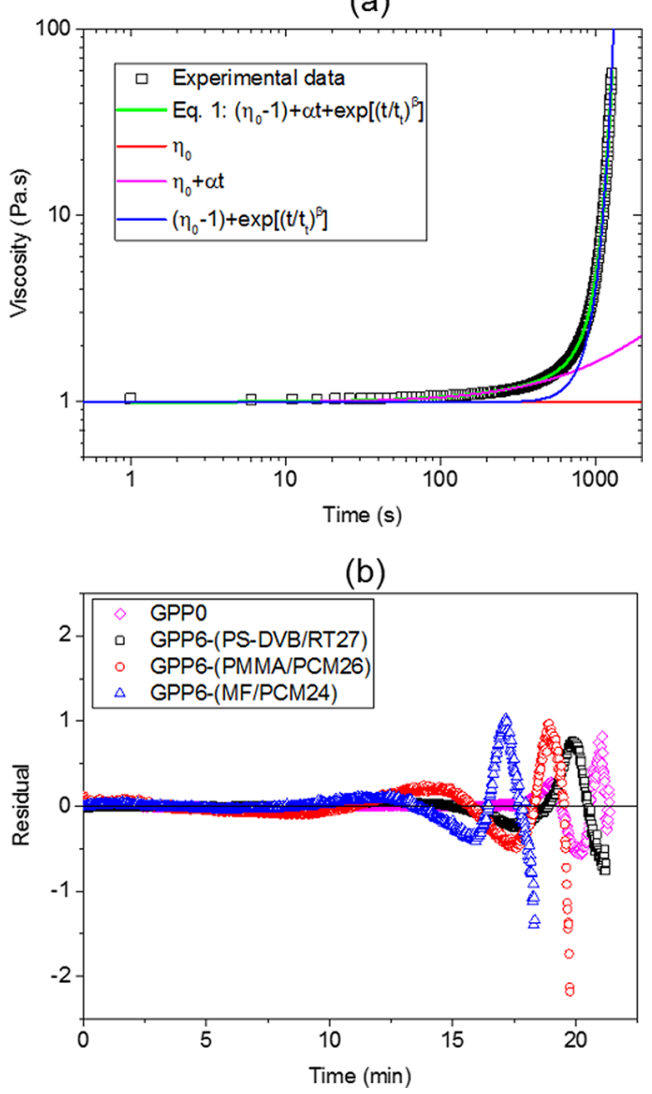

Figure 7. (a) Viscosity of the geopolymer paste without MPCM as a function of time at $20^{\circ} \mathrm{C}$. The symbols are experimental values (every fifth point is shown). The lines illustrate how the various parts of eq 1 model the different stages of the experimental data. (b) Residuals between experimental and fitted data as a function of time for the viscosity of the geopolymer paste without MPCM and with 6 wt \% MPCM. microcapsules are added. ${ }^{11}$ Water can be adsorbed onto the surfaces of the microcapsules. A higher surface area can therefore reduce the free water in the sample, thereby increasing the viscosity. In addition, as the concentration of microcapsules increases, the distance between the microcapsules becomes shorter, causing an obstruction of the movement of the fluid around them, which results in higher viscosity. ${ }^{11,30}$ The increase in the initial viscosity $\left(\eta_{0}\right)$ as a function of MPCM concentration is fastest for MF/PCM24 and slowest for PS-DVB/RT27. This might reflect the polar and nonpolar natures of the microcapsule shells. The hydrophobic PS-DVB/RT27 adsorbs much less water on the surface than MF/PCM24 and PMMA/PCM26 (Figure 2) and therefore affects the initial viscosity $\left(\eta_{0}\right)$ to a smaller degree (Figure $8 \mathrm{a})$. The initial viscosity $\left(\eta_{0}\right)$ increases faster when the concentration is raised for MF/PCM24 than for PMMA/ PCM26. However, according to Figure 2, PMMA/PCM26 adsorbs more water than MF/PCM24. The different testing conditions can contribute to this discrepancy. For the trappedwater test, the long immersion time $(24 \mathrm{~h})$ and the low viscosity of the alkaline solution allows the solution to easily penetrate deeply inside the structure of the PMMA/PCM26 agglomerates. Accordingly, all the single PMMA/PCM26 microcapsules can be covered by the alkaline solution, thereby causing more water to be adsorbed by PMMA/PCM26 compared with by MF/PCM24. However, for the rheology test, the higher viscosities of the geopolymer paste and the shorter contact times might prevent water from penetrating into the PMMA/PCM26 agglomerates. This can cause a lower effective water adsorption, because only the outer parts of the agglomerates adsorb water.

The precursor kinetic constant, $\alpha$, which indicates how fast the viscosity increases during the first stage, rises as the microcapsule concentration becomes higher (Figure 8c). This indicates that the reaction forming the geopolymer precursor and monomer is faster. When the microcapsule concentrations are raised, $\alpha$ increases much faster for the MPCMs with polar
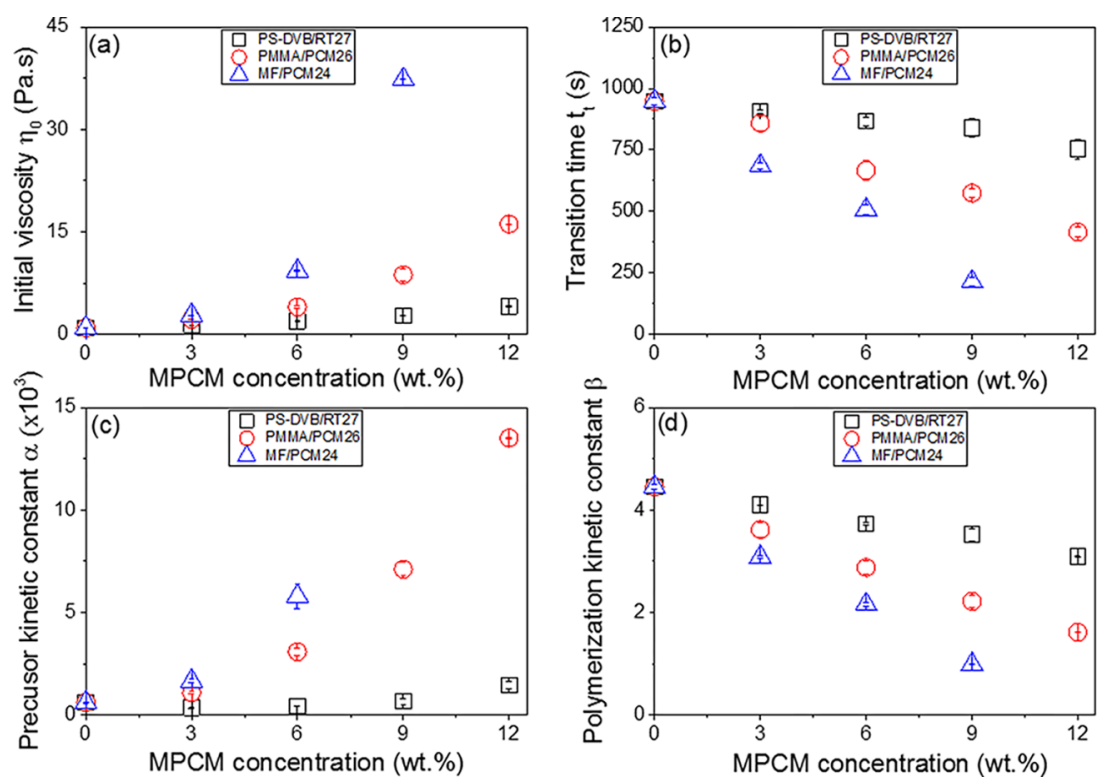

Figure 8. Rheological parameters of the geopolymer paste as functions of microcapsule concentration obtained by fitting eq 1 . (a) Initial viscosity, $\eta_{0}$; (b) transition time, $t_{t}$; (c) precursor kinetic constant, $\alpha$; and (d) polymerization kinetic constant, $\beta$. MF/PCM 24 could not be measured at the highest concentration because the reaction rate was too fast. 
groups on the polymer shells (MF/PCM24 and PMMA/ PCM26) than for PS-DVB/RT27, which has a nonpolar shell. As for $\eta_{0}, \alpha$ increases faster for MF/PCM24 than for PMMA/ PCM26. This suggests that the faster reaction rates forming the geopolymer precursor and monomer are due to the reduction of free water in the sample when water is adsorbed onto the microcapsule surfaces. Less free water might increase the concentration of the $\mathrm{Si}-\mathrm{Al}$ source material (Figure 5) in the liquid phase, thereby speeding up the reaction rate. It should be noted that the precursor kinetic constant, $\alpha$, of the geopolymer paste containing 9 wt \% MF/PCM 24 gave a slightly negative value after fitting to eq 1 . This is unrealistic because the viscosity increases with time (Figure 9). It is

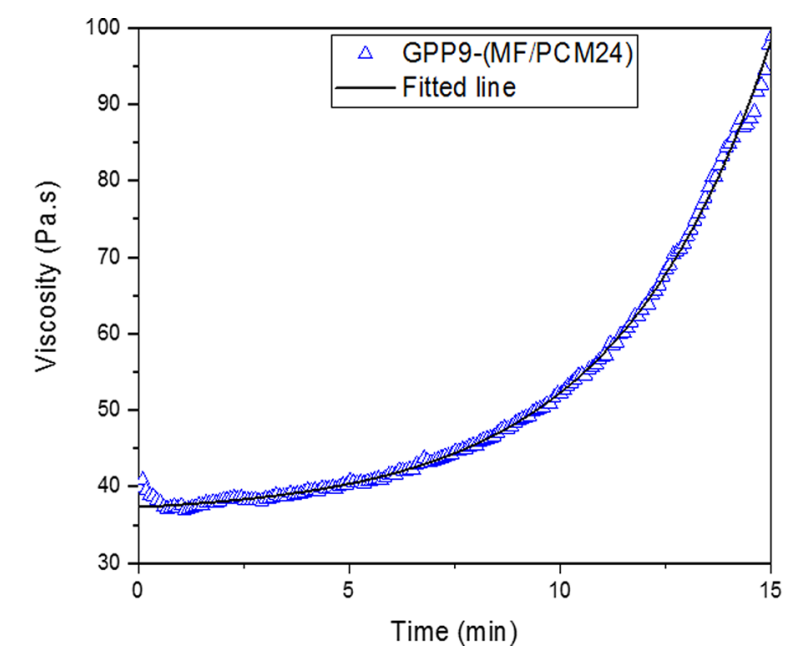

Figure 9. Viscosity of the geopolymer paste containing $9 \mathrm{wt} \% \mathrm{MF} /$ PCM24 as a function of time at $20{ }^{\circ} \mathrm{C}$. The symbols are experimental values (every fifth point is shown). The line shows the fitted values according to eq 1 with the precursor kinetic constant, $\alpha$, fixed equal to 0.

possible that at this high concentration of MF/PCM24 (9 wt $\%)$, the formation of the precursor during Stage I occurs very fast (i.e., it mostly finishes during the 7 min mixing process, Figure 6a). Accordingly, the measured viscosity only represents Stage II of the geopolymerization reaction. Working from this assumption, the precursor kinetic constant, $\alpha$, of the geopolymer paste containing 9 wt \% MF/PCM24 was set to 0 during the fitting procedure. As can be seen from Figure 9, this assumption seems reasonable because the fitted line is in good agreement with the experimental data, with a high value of $R^{2}(0.99)$.

The transition time $\left(t_{t}\right)$ from Stage I to Stage II indicates where the viscosity curve goes from the initial moderate increase to a much steeper curve (Figure 6a). As can be seen from Figure $8 \mathrm{~b}, t_{t}$ decreases when more MPCM is added to the samples, and the decline is most pronounced for MF/PCM24 and least evident for PS-DVB/RT27. This is in agreement with the faster formation of the geopolymer precursor and monomer for MF/PCM24. Interestingly, the polymerization kinetic constant, $\beta$, decreases at higher concentrations of microcapsules, illustrating that at Stage II, the geopolymerization reaction is slowed down by the addition of MPCM. As for the other parameters, the concentration dependence is strongest for MF/PCM24 and weakest for PS-DVB/RT27. The slower reaction rates are probably caused by the higher viscosities of the systems, which slow down the transportation of monomers to build up the 3-D structure.

\section{CONCLUSION}

A new rheological model was successfully developed to investigate the effect of microcapsules on the time-dependent viscosity of a geopolymer paste, obtaining good correlation with the geopolymerization reaction.

The important role of the hygroscopic nature, the sizes and concentrations of microcapsules on the time-dependent viscosity and geopolymerization-reaction rate were investigated. It was found that a higher microcapsule concentration caused an increase of initial viscosity, $\eta_{0}$; faster reaction rates for the formation of the geopolymer precursor and monomer; and a shorter transition time, $t_{t}$, to the change from the first stage (the formation of the precursor and monomer) to the second stage (geopolymer formation). Interestingly, at higher concentrations of microcapsules, the polymerization kinetic constant, $\beta$, decreased. This demonstrates that the geopolymerization reaction during the second stage is slowed down by the addition of MPCM, probably as a result of the higher viscosities. Overall, MF/PCM24, which has a polymer shell containing polar functional groups and the smallest size distribution (mean size of $21 \mu \mathrm{m}$ ), was found to have the strongest impact on the time-dependent viscosity and geopolymerization-reaction rate of the geopolymer paste when the concentration of MPCM was raised, whereas the weakest dependency was found for PS-DVB/RT27, which has a hydrophobic polymer shell. This effect is probably due to the higher amount of water adsorbed onto the microcapsules with more polar functional groups. The PMMA/PCM26 microcapsules affected the viscosities less than the MF/PCM24 microcapsules, although both of these microcapsules had shells with polar groups. The reason for this is probably the agglomerated nature of PMMA/PCM26, which provides a smaller effective surface area on which the water can adsorb.

The developed model can be used as a quantitative tool to design the mixing recipe and mixing process of a geopolymer paste containing MPCM. Further work will focus on the effects of microencapsulated phase-change materials on the rheology and geopolymerization reactions of geopolymer mortar and geopolymer concrete for buildings applications.

\section{ASSOCIATED CONTENT}

\section{Supporting Information}

The Supporting Information is available free of charge on the ACS Publications website at DOI: 10.1021/acs.iecr.8b01961.

Microstructures and sizes of single microcapsules, additional DSC thermograms of different types of microcapsules for determining microcapsule melting points and latent heats, and additional optical-microscope images of microcapsules before and after immersion in alkaline activator solution for $24 \mathrm{~h}$ (PDF)

\section{AUTHOR INFORMATION}

\section{Corresponding Author}

*E-mail: anna.l.kjoniksen@hiof.no.

ORCID $\odot$

Vinh Duy Cao: 0000-0001-5387-3874

Manuel Carmona: 0000-0002-1464-5067 
Anna-Lena Kjøniksen: 0000-0003-4864-4043

\section{Notes}

The authors declare no competing financial interest.

\section{ACKNOWLEDGMENTS}

We gratefully acknowledge funding from the Research Council of Norway, project number 238198. The authors gratefully acknowledge Rino Nilsen and Trond Atle Drøbak at Østfold University College for their assistance with laboratory work.

\section{REFERENCES}

(1) Benhelal, E.; Zahedi, G.; Shamsaei, E.; Bahadori, A. Global strategies and potentials to curb $\mathrm{CO} 2$ emissions in cement industry. J. Cleaner Prod. 2013, 51, 142-161.

(2) Chen, C.; Habert, G.; Bouzidi, Y.; Jullien, A. Environmental impact of cement production: detail of the different processes and cement plant variability evaluation. J. Cleaner Prod. 2010, 18, 478485.

(3) Chen, C.; Habert, G.; Bouzidi, Y.; Jullien, A. Environmental impact of cement production: detail of the different processes and cement plant variability evaluation. J. Cleaner Prod. 2010, 18, 478485.

(4) Duxson, P.; Fernandez-Jimenez, A.; Provis, J. L.; Lukey, G. C.; Palomo, A.; van Deventer, J. S. J. Geopolymer technology: the current state of the art. J. Mater. Sci. 2007, 42, 2917-2933.

(5) Zuhua, Z.; Xiao, Y.; Huajun, Z.; Yue, C. Role of water in the synthesis of calcined kaolin-based geopolymer. Appl. Clay Sci. 2009, 43, 218-223.

(6) Directive 2002/91/EC of the European Parliament and of the Council of 16 December 2002 on the energy performance of buildings; European Union: Brussels, 2002.

(7) Directive 2010/31/EU of the European Parliament and of the Council of 19 May 2010 on the energy performance of buildings; European Union: Brussels, 2010.

(8) Hunger, M.; Entrop, A. G.; Mandilaras, I.; Brouwers, H. J. H.; Founti, M. The behavior of self-compacting concrete containing micro-encapsulated Phase Change Materials. Cem. Concr. Compos. 2009, 31, 731-743.

(9) Wei, Z.; Falzone, G.; Wang, B.; Thiele, A.; Puerta-Falla, G.; Pilon, L.; Neithalath, N.; Sant, G. The durability of cementitious composites containing microencapsulated phase change materials. Cem. Concr. Compos. 2017, 81, 66-76.

(10) Eddhahak-Ouni, A.; Drissi, S.; Colin, J.; Neji, J.; Care, S. Experimental and multi-scale analysis of the thermal properties of Portland cement concretes embedded with microencapsulated Phase Change Materials (PCMs). Appl. Therm. Eng. 2014, 64 (1-2), 3239.

(11) Cao, V. D.; Pilehvar, S.; Salas-Bringas, C.; Szczotok, A. M.; Rodriguez, J. F.; Carmona, M.; Al-Manasir, N.; Kjøniksen, A.-L. Microencapsulated phase change materials for enhancing the thermal performance of Portland cement concrete and geopolymer concrete for passive building applications. Energy Convers. Manage. 2017, 133, $56-66$.

(12) Pilehvar, S.; Cao, V. D.; Szczotok, A. M.; Valentini, L.; Salvioni, D.; Magistri, M.; Pamies, R.; Kjøniksen, A.-L. Mechanical properties and microscale changes of geopolymer concrete and Portland cement concrete containing micro-encapsulated phase change materials. Cem. Concr. Res. 2017, 100, 341-349.

(13) Shadnia, R.; Zhang, L.; Li, P. Experimental study of geopolymer mortar with incorporated PCM. Construction and Building Materials 2015, 84, 95-102.

(14) Hunger, M.; Entrop, A. G.; Mandilaras, I.; Brouwers, H. J. H.; Founti, M. The behavior of self-compacting concrete containing micro-encapsulated Phase Change Materials. Cem. Concr. Compos. 2009, 31, 731-743.
(15) Drissi, S.; Eddhahak, A.; Caré, S.; Neji, J. Thermal analysis by DSC of Phase Change Materials, study of the damage effect. Journal of Building Engineering 2015, 1, 13-19.

(16) Cao, V. D.; Salas-Bringas, C.; Schüller, R. B.; Szczotok, A. M.; Hiorth, M.; Rodriguez, J. F.; Carmona, M.; Kjøniksen, A.-L. Rheological and thermal properties of suspensions of microcapsules containing phase change materials. Colloid Polym. Sci. 2018, 296, 981-988.

(17) Vickers, L.; Rickard, W. D. A.; van Riessen, A. Fire-Resistant Geopolymers: Role of Fibres and Fillers to Enhance Thermal Properties; SpringerBriefs in Materials Series; Springer: Singapore, 2015.

(18) Szczotok, A. M.; Carmona, M.; Kjøniksen, A.-L.; Rodriguez, J. F. Equilibrium adsorption of polyvinylpyrrolidone and its role on thermoregulating microcapsules synthesis process. Colloid Polym. Sci. 2017, 295, 783-792.

(19) Micronal DS 5038 X; Datasheet; Microtek Laboratories: Dayton, OH, 2017.

(20) MPCM 24D; Datasheet MPDS3300-0026; Microtek Laboratories: Dayton, $\mathrm{OH}, 2017$.

(21) Sakulich, A. R.; Bentz, D. P. Increasing the Service Life of Bridge Decks by Incorporating Phase-Change Materials to Reduce Freeze-Thaw Cycles. J. Mater. Civ. Eng. 2012, 24, 1034-1042.

(22) Ito, S.; Hashimoto, M.; Wadgaonkar, B.; Svizero, N.; Carvalho, R. M.; Yiu, C.; Rueggeberg, F. A.; Foulger, S.; Saito, T.; Nishitani, Y.; Yoshiyama, M.; Tay, F. R.; Pashley, D. H. Effects of resin hydrophilicity on water sorption and changes in modulus of elasticity. Biomaterials 2005, 26, 6449-6459.

(23) Suwan, T.; Fan, M.; Braimah, N. Internal heat liberation and strength development of self-cured geopolymers in ambient curing conditions. Construction and Building Materials 2016, 114, 297-306.

(24) Lucas, S. S.; Senff, L.; Ferreira, V. M.; Barroso de Aguiar, L.; Labrincha, J. A. Fresh State Characterization of Lime Mortars with PCM Additions. Appl. Rheol. 2010, 20 (6), 63162.

(25) Norvell, C.; Sailor, D. J.; Dusicka, P. The Effect of Microencapsulated Phase-Change Material on the Compressive Strength of Structural Concrete. J. Green Building 2013, 8, 116-124.

(26) Beyhan, B.; Cellat, K.; Konuklu, Y.; Gungor, C.; Karahan, O.; Dundar, C.; Paksoy, H. Robust microencapsulated phase change materials in concrete mixes for sustainable buildings. Int. J. Energy Res. 2017, 41, 113-126.

(27) Cao, V. D.; Pilehvar, S.; Salas-Bringas, C.; Szczotok, A. M.; Valentini, L.; Carmona, M.; Rodriguez, J. F.; Kjøniksen, A.-L. Influence of microcapsule size and shell polarity on thermal and mechanical properties of thermoregulating geopolymer concrete for passive building applications. Energy Convers. Manage. 2018, 164, 198-209.

(28) Wang, K.-T.; Tang, Q.; Cui, X.-M.; He, Y.; Liu, L.-P. Development of near-zero water consumption cement materials via the geopolymerization of tektites and its implication for lunar construction. Sci. Rep. 2016, 6, 29659.

(29) Mustafa Al Bakri, A. M.; Kamarudin, H.; Bnhussain, M.; Khairul Nizar, I.; Mastura, W. I. W. Mechanism and Chemical Reaction of Fly Ash Geopolymer Cement - A Review. J. Asian Sci. Res. 2011, 1, 247-253.

(30) Kanellopoulos, A.; Giannaros, P.; Al-Tabbaa, A. The effect of varying volume fraction of microcapsules on fresh, mechanical and self-healing properties of mortars. Construction and Building Materials 2016, 122, 577-593. 